\title{
CONFERÊNCIA E DISCURSOS.
}

\section{O Japão de hoje.}

\author{
Nobuo Okuchi \\ Cônsul Geral do Japão em São Paulo.
}

Constitui, para mim, uma grande honra, poder falar sobre o Japão, esta noite, no Departamento de Direito Internacional do Curso de Doutoramento da Faculdade de Direito da Universidade de São Paulo, valendo-me da oportunidade que me foi concedida, de estar com este esplêndido grupo de jovens, em cujos ombros pesa a responsabilidade de dirigir os destinos do Brasil de amanhã.

Estive considerando a possibilidade de versar um tema especial, eis que os senhores estão fazendo a especialização em Direito Internacional. Mas tomei a liberdade de apresentar aos senhores uma imagem geral do Japão contemporâneo, sem, contudo, deixar de lado aspectos fundamentais. Por isso mesmo, dei a esta palestra o título O Japão de hoje.

É que, apesar de nos últimos tempos vir recebendo referências elogiosas como "A Terceira Potência Econômica", ou "O Milagre Japonês", em virtude do progresso econômico conseguido a partir das cinzas da guerra, o Japão é, entre os estrangeiros, relativamente desconhecido. Muitos há ainda que perguntam "se os japoneses dormem sobre palhas" ou "se existem indústrias de automóveis no Japão" Não faz muitos anos,

Palestra proferida na Faculdade de Direito da Universidade de São Paulo, em 27 de setembro de 1971. 
quando numa escola da Austrália se pediu aos alunos que escrevessem uma composição com o tema "Japão", a maioria deles escolheu como assunto O Monte Fuji ou A Gueixa.

Japão e Brasil são países situados geograficamente longe, em polos opostos da terra. É certo que no Brasil existe uma Colônia Japonesa de cerca de 700.000 (setecentos mil) membros, e as relações nipo-brasileiras são extremamente amistosas. Mas, o conhecimento que o povo brasileiro tem sobre o Japão não parece de todo satisfatório. Por isso, e também porque é esta a primeira vez que venho falar nesta Faculdade, tomei a liberdade de discorrer de modo geral sobre o Japão. E neste ponto, quero solicitar desde já a compreensão dos senhores.

Por outro lado, dada.a insuficiência do meu Portugues, peço a permissão dos senhores para ler a palestra que preparei para esta noite. Talvez lhes seja penoso ouvir-me, mas conto com a benevolência de todos.

O Japão é um pequeno país montanhoso. Com a derrota na guerra, perdeu a Sakalina do Sul, Coréia e Formosa. Atualmente seu território se compõe de quatro ilhas, a saber: Hokkaido, Honshu, Shikoku e Kyushu. Sua superfície é de aproximadamente $370.000 \mathrm{~km}^{2}$ (trezentos e setenta mil quilômetros quadrados) que corresponde a menos de $0,3 \%$ (três décimos por cento) da superfície terrestre do globo, e a $1 / 23$ (um vinte e três ávos) do território brasileiro. Além disso, $80 \%$ (oitenta por cento) da sua área é montanhosa, sendo de apenas $16 \%$ (dezesseis) por cento a superfície arável. Quem visita o Japão não deixa de ficar surpreso em ver lavrados terrenos que ficam no topo das montanhas.

Quanto à população, o Japão é ainda super-povoado. Em um país pequeno moram mais de 100.000000 (cem milhões) de pessoas. Depois da guerra baixou muito o índice de natalidade, mas como o índice de mortalidade também decresceu, a população ainda continua a crescer. O Japão é o quinto 
país mais populoso do mundo, depois da China Comunista, India, Estados Unidos da América, Indonésia e Paquistão. A densidade populacional do Japão é de 266 (duzentos e sessenta e seis) pessoas por quilômetro quadrado, sendo a terceira do mundo, depois da Holanda e da Bélgica. Se fôr tomada como base a superfície arável, a densidade populacional do Japão passa a ocupar o primeiro lugar. Existe uma grande concentração humana em Tokyo, que, com seus 12000000 (doze milhões) de habitantes, ultrapassou Nova York e é a maior cidade do mundo.

O Japão é um país pobre em recursos naturais. Quase toda matéria-prima de que necessita é importada. $\mathrm{O}$ algodão, a lã, a bauxita e a borracha natural, em $100 \%$ (cem por cento) $\mathrm{O}$ açucar, o minério de estanho, o minério de ferro e petróleo bruto em $90 \%$ (noventa por cento) O trigo, a soja e o sal, em $60 \%$ (sessenta por cento) ou $70 \%$ (setenta por cento)

Por aí os senhores podem avaliar quanto o comércio exterior é importante para o Japão. Para o consumo de uma enorme população que continua a crescer dentro de um pequeno território, aquêle país importa grande quantidade de alimentos e de matérias-primas. E, para poder importar, é obrigado a vender no exterior os produtos manufaturados ou semiacabados.

Por isso, pode-se dizer que o comércio exterior é o centro vital do Japão.

É inacreditável que um país minúsculo, sem recursos naturais, houvesse por quase quatro anos desafiado as grandes potências, na maior guerra da história da humanidade. As conseqüências seriam para êle desastrosas.

Com a derrota, o Japão ficou abalado tanto materialmente como espiritualmente. Perdeu $45 \%$ (quarenta e cinco por cento) de seu território, ficou com os recursos naturais esgotados e o território arrazado. Tokyo e as demais grandes cidades reduziram-se a cinzas. 
A conjuntura econômica do após guerra era das piores, comparada com a situação de antes da guerra. O Produto $\mathrm{Na}$ cional Bruto de 1946 (mil novecentos e quarenta e seis) correspondia a apenas $65 \%$ (sessenta e cinco por cento) dos anos de 1934 (mil novecentos e trinta e quatro) - 1936 (mil novecentos e trinta e seis) A produção industrial caíra para $28 \%$ (vinte e oito por cento) Além disso, o Japão havia perdido todo o mercado estrangeiro. Noventa por cento de sua frota mercante estava no fundo do mar. Essa crise econômica trouxe uma inflação de graves proporções, e levou o Japão a um estado de completa paralização.

O povo japones sofreu com a derrota um grande abalo espiritual. Tendo perdido a confiança no caminho que vinha trilhando, e nos padrões do correto e do errado, viu ruir completamente de um momento para outro, o seu sistema moral. Sem padrões de moral, e duvidando dos rumos do passado e do presente, o povo teve de procurar os caminhos da recuperação vagando desorientado em meio ao temor e ao cansaço.

Quem acreditaria, então que o Japão se recuperasse ràpidamente? Mas o povo não ficou a vaguear por muito tempo em meio às ruínas, e começou a enfrentar a tarefa da reconstrução nacional. O povo passou então a aspirar uma rápida recuperação econômica, através das relações com todos os demais países, e a reaquisição da soberania para, como uma nação pacifista, integrar a comunidade internacional.

Foi lutando diuturnamente, em busca desses objetivos, que o Japão conseguiu, em vinte anos, alçar-se novamente como uma das Nações mais prósperas do mundo.

Há realmente aspectos notáveis na recuperação e crescimentos econômicos do Japão nos após-guerra. Em 1951 (mil novecentos e cinqüienta e um) o produto nacional bruto, em 1953 (mil novecentos e cinquienta e três) o poder aquisitivo, em 1959 (mil novecentos e cinqüenta e nove) o volume de exportação havia cada qual atingido o nível de antes da guerra. $\mathrm{O}$ progresso econômico continuou em altos índices. 
O Produto Nacional Bruto que em 1950 (mil novecentos e cinqüenta) era o sétimo no mundo livre, passou em 1960 (mil nevecentos e sessenta) a ser o quinto, e em 1968 (mil novecentos e sessenta e oito ) a ser o segundo, logo depois dos Estados Unidos da América, sendo que no mundo todo é o terceiro, seguindo-se aos Estados Unidos e à União Soviética. Especialmente a indústria teve um desenvolvimento notável, e sua produção de navios, automóveis, televisores, rádios, aço, cimento, fertilizantes, energia elétrica, petróleo refinado, ácido sulfúrico, estanho, fibras sintéticas, fios de algodão, arroz, pescados, se situa cada qual nos primeiros cinco lugares do mundo. Em 1968 (mil novecentos e sessenta e oito) a produção de aço e de automóvel ocupava o segundo lugar no mundo, a produção naval, bem como a produção de caminhões em primeiro lugar, e a produção de fibras sintéticas o segundo.

Também no que toca ao comércio exterior, alguns fatos são marcantes. O volume de exportações que em 1950 (mil novecentos e cinquienta) era de apenas US\$820.000.000.00 (oitocentos e vinte milhões de dólares) passou em 1970 (mil novecentos e setenta) a ser de US\$19 300000.000 .00 (dezenove bilhões e trezentos milhões de dólares) As importações, nesse mesmo período, cresceram de US\$970.000.000.00 (novecentos e setenta milhões de dólares) para US\$ 18.900.000.000,00 (dezoito bilhões, novecentos milhões de dólares) Esse volume de exportações corresponde a 6,1\% (seis vírgula um por cento) e o de importação a 5,8\% (cinco vírgula oito por cento) respectivamente, dos volumes de exportação e de importação de todo o mundo livre. O que merece ser notado é que os produtos que participam das exportações japonesas tem variado no correr dos anos. No passado, o Japão exportava principalmente tecidos e artigos da indústria leve, mas atualmente na pauta das exportações japonesas ocupam lugar de maior destaque os produtos da indústria pesada e da indústria química. Estes produtos, que antes da guerra eram apenas $20 \%$ (vinte por cento) do volume exportado, eram 37,2\% (trinta e sete vírgula dois por cento) em 1956 
(mil novecentos e cinqüenta e seis) e são 65\% (sessenta e cinco por cento) atualmente.

Como todos sabem, as máquinas fotográficas e os binóculos japoneses são famosos pela precisão, e os rádios transistores daquele país são altamente conceituados em qualquer lugar do mundo, sendo que a procura supera a própria produção. Especialmente os automóveis de pequeno e médio porte vêm tendo grande aceitação na Ásia e nos Estados Unidos. O Japão já deixou de ser "o país dos brinquedos" e dos kimonos"

Essa expansão do comércio exterior reflete-se claramente na posição do Japão com referência à moeda estrangeira. As reservas de dólar no Japão eram de US\$ 1330.000 .000 (um bilhão trezentos e trinta milhões de dólares) em 1959 (mil novecentos e cinqüenta e nove), eram da ordem de US\$ 4390.000 .000 (quatro bilhões trezentos e noventa milhões de dólares) nos fins de 1970 (mil novecentos e setenta), e, com a recente crise do dólar, as reservas em moeda estrangeira atingiram US\$ 12.000.000.000 (doze bilhões de dólares) Essa cifra é superior à reserva norte-americana de moeda estrangeira, e segue-se à reserva da República Federal da Alemanha.

Esse crescimento econômico trouxe uma natural melhora nas condições de vida do povo. Quase todas as famílias possuem geladeira, máquina de lavar, panela automática de cozer arroz e televisão.

Entre Tokyo e Osaka corre o trem super-expresso a uma velocidade de $240 \mathrm{~km}$ (duzentos e quarenta quilômetros) por hora, permitindo idas e vindas, entre essas duas cidades distantes, num mesmo dia. Essa ferrovia será estendida no próximo ano por mais $200 \mathrm{~km}$ (duzentos quilômetros) a oeste.

As grandes empresas jornalísticas trazem quase todos os anos as mais famosas obras de arte e os mais ilustres artistas. Será hoje possível ver na cidade de Tokyo a própria Vênus de Milo. 
As diversões evoluiram também, e os jovens têm em cada estação do ano uma temporada esportiva, desde o esqui e a patinação no inverno, até o banho de mar e o alpinismo no verão. As pessoas de mais idade percorrem o país todo e gozam as férias em estações balneárias.

Como terá sido possível uma expansão econômica tão marcante? Penso que é possível citar alguns fatores desse progresso.

Em primeiro lugar, as duas grandes reformas do após guerra, consistentes na Reforma Agrária e na Extinção dos "Zaibatsu" (Sociedades Monopolísticas de Família)

A Reforma Agrária despertou na população rural as necessidades reais que nela existiam latentes, o que abriu um grande mercado consumidor à produção industrial. A extinção dos "Zaibatsu" no após guerra, juntamente com a instituição da Lei Anti-Trust, possibilitou a remoção de um obstáculo à sadia concorrência, e a moralização dos custos.

Em segundo lugar, citaria o "alto índice de poupança", como um dos fatores do desenvolvimento.

Há no povo japonês um tradicional espírito de poupança. Mas, o índice de poupança do após-guerra atingiu índices muito superiores ao do período anterior à guerra, e ao de outros países. O índice de poupança individual que nos países altamente industrializados gira em torno de $10 \%$ (dez por cento) de sua renda, alcançou no Japão de 17 (dezessete) a $19 \%$ (dezenove por cento).

A poupança era canalizada para os bancos, e servia assim de fundo para favorecer o aparelhamento industrial ou o capital de giro das empresas.

Em terceiro lugar, cito a "abundante mão de obra e elevado nível de instrução".

Havia no Japão uma grande força de trabalho sub-empregada (under-employed), seja na agricultura, nas pequenas 
e médias empresas, em lojas a varejo, e outras atividades. Foi então possível aproveitar essa força de trabalho aplicada em atividades de baixo rendimento, para atividades modernas, de alto rendimento.

Por exemplo, o segundo e o terceiro filho de uma fa mília de agricultores, que trabalhavam no cultivo da terra ajudando os pais e o irmão mais velho. Por mais que eles se dedicassem, não aumentava em muito a rentabilidade da propriedade agrícola. Se, porém, eles fossem trabalhar numa fábrica da cidade, a sua produtividade seria inumeras vezes maior.

Mas a quantidade de mão de obra não basta. E importante que a mão de obra tenha qualidades. E preciso que o trabalhador tenha suficiente instrução para assimilar técnicas novas e passe a trabalhar de modo produtivo.

Pode-se dizer que o elevado índice educacional dos japoneses lhes permitiu formar uma força de trabalho altamente qualificada, que a produtividade industrial estava a exigir. Não havia, como não há, analfabetismo no Japão.

Em quarto lugar, a "renovação tecnológica" As empresas japonesas do após-guerra trouxeram dos outros países, especialmente dos Estados Unidos as técnicas novas que não puderam conseguir durante a guerra.

Especialmente a partir de 1960 (mil novecentos e sessenta) as empresas investiram somas fabulosas no melhoramento dos equipamentos da técnica.

O rápido crescimento das exportações de navios, rádios, televisores, automóveis e motocicletas no após-guerra se deve à concentração nos investimentos da capital.

Em quinto lugar, a "transformação na estrutura industrial do Japão". Isto é, a transformação da indústria leve em indústria pesada. Antes da guerra, o investimento em equipamentos industriais consumia as divisas externas, porque se 
importavam os equipamentos, mas, depois da guerra, a grande parte dos mais importantes equipamentos é fabricada no Japão, possibilitando o investimento sem consumo da divisa externa. E a produção de máquinas e equipamentos no próprio país aumentou cumulativamente a produção nacional e influiu nas atividades produtivas dos mais variados setores, proporcionando um incremento geral da produção.

Em sexto lugar, aponto a "redução das despesas de natureza militar e a extinção dos gastos com as colônias"

Antes da guerra, cêrca de $10 \%$ (dez por cento) da Renda Nacional Bruta eram destinadas a esses fins. Mas, tendo - Japão perdido a guerra, perdeu as colônias, e suas despesas de natureza militar ficaram extraordinàriamente reduzidas. Atualmente as despesas com a defesa nacional não passam de $1,4 \%$ (um vírgula quatro por cento) da Renda Naciona! Bruta. $\mathrm{O}$ que se economizou nesta parte pode ser investido na expansão econômica

Em sétimo lugar a "tendência mundial para o livre comércio" poderia ser apontado como uma das causas do grande desenvolvimento econômico do Japão. Os diversos países já tem a amarga experiência da política de autarquia que procura o equilíbrio restritivo da economia mundial, que lhes criou atritos de natureza política e militar, e que os levou à guerra mundial. Depois da guerra, os países se esforçaram em desenvolver suas economias, ampliando o intercâmbio comercial recíproco, pela apolítica do equilíbrio ampliativo.

O comércio internacional vem se expandindo graças ao rompimento ou a atenuação das restrições cambiais e comerciais. Essa tendência da economia mundial favoreceu aqueles países que, como o Japão, têm poucos recursos naturais, e dependem da exportação de seus produtos.

O rádio transistorizado, por exemplo, é também fabricado nos Estados Unidos, mas, no sistema do livre comércio, 
o artigo japones poderá entrar no mercado daquele país, seja por ser mais barato, seja por possuir boa qualidade.

Além das causas a que me referi até agora, outros fatores poderiam ser mencionados, como tendo contribuído para o rápido crescimento econômico do Japão, tais como:

a) A lealdade coletiva dos trabalhadores japoneses com relação às empresas;

b) Sistema Financeiro Peculiar, a política clarividente das autoridades monetárias, e a habilidade dos administradores de empresa;

c) Política inteligente do Governo e existência de excelente estrutura burocrática no setor econômico;

d) Dinâmico espírito comercial dos homens de negócios.

Até aqui vim discorrendo sobre os fatores econômicos que teriam contribuído para o desenvolvimento do Japão, mas gostaria de salientar ainda mais um aspecto que, embora não seja de natureza econômica, nem por isso se reveste de menor importância.

Quero referir-me ao espírito japones que se traduz no senso de independência, na diligência, no entusiasmo pelo trabalho, espírito de auto-sacrifício, vida regular, capacidade de assimilar coisas novas, especialmente do estrangeiro.

Pode-se dizer que o grande progresso econômico do Jagão é o resultado do esforço e da indomável energia do povo japones.

Apesar de até agora vir falando dos aspectos positivos da economia japonesa, não se pode negar que o Japão enfrenta inúmeros problemas de ordem econômica.

A primeira questão consiste na carência da mão-de-obra. A excelente força de trabalho, um dos sustentáculos do cres- 
cimento econômico japones começou a acusar, desde 1960 , (mil novecentos e sessenta), uma certa carência. Essa carência se acentuou a partir de 1965 (mil novecentos e sessenta e cinco), pelos seguintes motivos:

a) Alteração na estrutura populacional em virtude da redução do índice de natalidade e de mortalidade;

b) Diminuição da mão-de-obra jovem, pelo aumento da população universitária;

c) Diversificação das atividades como resultado da propriedade;

d) Redução da jornada de trabalho.

A segunda questão consiste no aumento do custo de vida, cujo índice anual de aumento entre 1961 (mil novecentos e sessenta e um) e 1965 (mil novecentos e sessenta e cinco) era de 6,2\% (seis vírgula dois por cento), e entre 1966 (mil novecentos e sessenta e seis) e 1970 (mil novecentos e setenta) era de 5,5\% (cinco vírgula cinco por cento) índices esses que superam o nível de aumento dos preços no comércio atacadista. A questão do custo de vida está para se tornar um dos problemas da política nacional.

A terceira questão se refere à falta de modernização das pequenas e médias empresas, e da agricultura.

Há no Japão um grande número de pequenas e médias empresas de baixa produtividade, a tal ponto que se fala até em "Dualismo" da econômia japonesa.

Por sua vez, a agricultura se ressente da falta de modernização, em virtude de:

a) o arroz continuar a ser o produto nacional;

b) a produtividade estar sendo mantida pela mecanização, já que a mão-de-obra rural está exau- 
rida com a concentração urbana da força de trabalho; e

c) a maioria dos lavradores se dedicar a atividades paralelas.

A quarta questão consiste no baixo investimento do capital social, e nos problemas da poluição.

Há enorme falta de habitações, estradas, jardins, rede de água e de esgotos. ciais.

A poluição se tornou um dos mais graves problemas so-

Pode-se dizer que essa falta de capital social é o resultado da política econồmica passada, de se dar prioridade à produção industrial.

A quinta questão se prende ao atrazo do Japão no sentido da economia aberta.

A partir de 1960 (mil novecentos e sessenta) a economia japonesa entrou no processo da internacionalização para se tornar aberta. Assim, o Governo promoveu, a partir de Julho de 1960 (mil novecentos e sessenta) a liberalização do intercâmbio comercial e do câmbio, e a partir de 1967 (mil novecentos e sessenta e sete) a liberalização das transações com o capital. Mas, alguns setores da produção continuam em atraso, e esse estado de coisas tem sido motivo para que os outros países, especialmente os Estados Unidos, venham insistindo na liberalização do comércio e do capital, julgada ainda insuficiente.

Além disso, o valor do Yen vem sendo criticado como artificial, e o Governo do Japão está sendo pressionado pelos outros países para valorizar a moeda.

Em virtude da recente crise do dólar, resultante das declarações do Presidente Nixon, o Japão não teve outra alternativa senão determinar a flutuação cambial do Yen, cuja va- 
lorização, embora não desejada, também se tornou uma questão de tempo.

A sexta questão se refere à falta de cooperação com o exterior. A ajuda do Japão aos países em vias de desenvolvimento foi em 1969 (mil novecentos e sessenta e nove) inferior a dos Estados Unidos, Alemanha e França, ocupando o quarto lugar.

A ajuda externa do Japão em relação ao seu Produto $\mathrm{Na}$ cional Bruto é de $0,76 \%$ (zero vírgula setenta e seis por cento), enquanto que a da Alemanha é de $1,3 \%$ (um vírgula três por cento) e a da França representa 1,24\% (um vírgula vinte e quatro por cento)

Por deliberação da Conferência sobre o Comércio Internacional da Organização das Nações Unidas, o Japão recebeu a recomendação de elevar sua ajuda externa de modo que a mesma alcance em 1975 (mil novecentos e setenta e cinco) a $1 \%$ (um por cento) do seu Produto Nacional Bruto, ou seja a cerca de US\$ 4.000.000.000 (quatro bilhões de dólares)

A aspiração do povo japones após a guerra era soerguer sua arruinada economia, readquirir sua soberania e voltar à comunhão internacional. Com a derrota, o Japão fora desmilitarizado e colocado sob a administração das forças de ocupação das Nações Unidas. Entretanto, em 1951 (mil novecentos e cinqüenta e um), era assinado o tratado de paz com o Japão, que entrou em vigor em abril de 1952 (mil novecentos e cinqüenta e dois), recuperando a tão aspirada soberania. Em 1956 (mil novecentos e cinquienta e seis) foi admitido na Organização das Nações Unidas, voltando ao convívio das nações. Ainda em 1956 (mil novecentos e cinqüenta e seis), o Japão firmou com a União Soviética, que não subscrevera o Tratado de Paz, um Acordo em separado.

A política externa do Japão repousa atualmente em três princípios. Em primeiro lugar, a determinação de prestigiar a Organização das Naçães Unidas. Em segundo lugar, ser um 
dos membros do mundo livre. Em terceiro lugar, reafirmar sua condição de ser um país asiático.

Como única vítima da bomba atômica, e conhecendo na carne o horror e a inutilidade da guerra, o povo japones sabe que é de seu dever lutar com todas as forças para evitar que uma nova guerra assole a humanidade.

Em 1947 (mil novecentos e quarenta e sete) o Japão adotou uma nova Constituição, cujo Artigo 9. ${ }^{\circ}$ (nono), declarando perante o mundo renunciar para sempre à guerra como meio para resolver as disputas internacionais, estabeleceu que o Japão é um país amante da paz. Trata-se de uma constituição única no mundo inteiro.

Contudo, a paz e a estabilidade do mundo não podem ser asseguradas somente por um país, exigindo a cooperação de todas as nações do mundo. Nesse sentido, a Organização das Nações Unidas desempenha um papel preponderante na promoção da colaboração internacional.

Sendo uma nação pacifista, é mesmo natural que o Japão, respeitando a Carta das Nações Unidas, e valendo-se do forum que é esse organismo internacional, promova uma diplomacia da paz. Na Organização das Nações Unidas o Japão desempenha um papel peculiar nas grandes questões, de mediador entre os países do Oeste e os países Afro-asiáticos. O Japão ainda atua como membro do Conselho de Segurança e do Conselho Econômico e Social. Malgrado as Nações Unidas não tenham podido desempenhar, tão completamente como seria de desejar, suas funçōes de organismo mundial para a paz, o Japão sempre lutou para o seu fortalecimento.

O Japão deseja a concretização da paz mundial, mas sempre no regime da liberdade e da democracia, e não aceita o sistema totalitário. Desse ponto de vista, o Japão pertence ao mundo livre e convive no concerto das Nações livres, comungando a mesma crença política. E por isso que tão logo foi 
concluído o tratado de paz, firmou o Tratado de Segurança com os Estados Unidos.

Todavia, o Japão não despreza as relações com os países comunistas. Não mantém ainda relações diplomáticas com a China Comunista, Coréia do Norte, Vietnã do Norte, e a República Democrática da Alemanha, mas mantém relações diplomáticas com os demais países do bloco comunista, procurando o intercâmbio econômico e cultural, sem interferir ros negócios internos desses países.

Com a União Soviética ainda tem questões não resolvidas acerca dos territórios do norte, mas, as relações diplomáticas melhoraram sensivelmente nos últimos anos.

O que merece ser observado é que uma parte do povo, especialmente a intelectualidade japonesa debate a neutralidade do Japão. Por mais estranho que pareça, tais pessoas tendem a criticar os Estados Unidos, numa atitude de auto-satisfação, taxando-os de país imperialista. Como para êles o ataque dos Estados Unidos se tornou uma espécie de profissão, tendem a defender a União Soviética e a China Comunista. O neutralismo para êles é claramente uma tendência para a esquerda. Por isso, são êles contrários ao Tratado de Segurança com os Estados Unidos. Mas a maioria do povo japones acredita na possibilidade da defesa da liberdade, em colaboração com os países do mundo livre, especialmente os Estados Unidos.

Por outro lado, é natural que o Japão, como um dos membros da Comunidade das Nações Asiáticas, siga a política de boa vizinhança com todos os países asiáticos. Depois da guerra, surgiram na Ásia vários países novos, os quais ainda não possuem uma base econômica estável. E preciso estender-lhes a mão de ajuda, para que possam prosperar econômicamente. Por isso é grande e crescente a responsabilidade do Japão, na sua condição de único país industrialmente desenvolvido. $\mathrm{O}$ governo e os líderes do Japão estão conscientes dessa respon- 
sabilidade, e vêm procurando prestar a cooperação econômica e técnica especialmente para os países da Âsia.

No passado, o Japão chegou a intervir indevidamente nos negócios internos dos seus vizinhos da Ásia, e foi mesmo chamado de invasor. Assim, é preciso cuidar para que, em razão da cooperação econômica e técnica, não venha o Japão a ser taxado de "econômicamente invasor"

Alguns países da Ásia já estão criticando o Japão de colocar os seus interesses econômicos em primeiro lugar.

A sobreposição dos seus interesses talvez tenha sido uma decorrência da necessidade de sua recuperação econômica, mas isso já não é mais possível.

Ao Japão cabe doravante sair de seu casulo.

Do ponto de vista da diplomacia japonesa, existem duas grandes questões, a recuperação dos territórios ao norte, e a questão da China Comunista.

Através de negociações com os Estados Unidos, ficou resolvido que Okinawa será devolvida ao Japão, e as providências para que isso se verifiquem em breve estarão sendo tomadas.

Quantos aos territórios ao norte, os mesmos ainda estão na mesma situação de quando foram ocupados pela União Soviética, sem perspectivas de devolução, em virtude da intransigente atitude da União Soviética. $\mathrm{O}$ povo japones anseia pela devolução desses territórios, como aspirou a devolução de Okinawa.

Afirmou uma vez o Primeiro Ministro Sato que "sem a devolução de Okinawa não existe o Japão de após guerra", mas o mesmo se poderá dizer com referência aos territórios do norte. É certo, contudo, que o Japão terá de continuar negociando pacientemente com a União Soviética para alcançar tal objetivo. 
A questão da China Comunista é extremamente comple$\mathrm{xa}$, em virtude de existirem duas Chinas. O Japão firmou o tratado de paz com a China Nacionalista de Formosa, mas com a República Popular da China, que fica no Continente, o Japão vem deixando de lado a questão política para intensificar apenas o intercâmbio econômico.

A China Continental, depois de realizar a revolução civil, reviu a sua política isolacionista e vem rapidamente conquistando o seu lugar na comunidade internacional. Grande número de países já reconheceu o seu governo como legítimo, e muitos outros estão em vias de fazề-lo. Nas Nações Unidas tornou-se decisivamente forte o movimento de admissão da China Comunista. Diante desse país vizinho que governa a maior parte de seu território, e que possui uma população de 700.000 .000 (setecentos milhões) de pessoas, tornou-se antinatural e difícil ao Japão deixar de lado o lado político.

Entretanto, a China Comunista vem adotando em relação ao Japão uma atitude muito rigorosa. Diz que a Formosa é parte inseparável do território da China, e as relações com a Formosa constituem assunto de política interna da China, de modo que a idéia de "duas Chinas" ou "uma China e uma Formosa" constitui intromissão nos assuntos internos da China, e esconde a intenção de dividir a China, sendo intolerável. Enquanto o Japão não reconhecer o governo da China Comunista como o único legítimo, não haverá restabelecimento das relações diplomáticas, dizem êles.

Entretanto, o Japão não pode esquecer que no conflito sino-japones foi Shangkai Chek o adversário, e foi com êle que firmou o Tratado de Paz. E que a China Nacionalista tem sido, desde a fundação da Organização das Nações Unidas, um membro cumpridor de seus compromissos internacionais. Não se pode esquecer que apesar de, por longos anos, haver sofrido a invasão dos japoneses, que inflingiram ao povo chinês danos materiais e morais, o General Shangkai Chek não se prevaleceu do fim da guerra para exigir indenizações ou apontar 
criminosos de guerra, tendo para com o Japão uma atitude magnânima.

Vista a questão à luz desta realidade histórica, não pode - Japão abandonar a China Nacionalista, apenas porque a China Comunista se tornou hoje uma potência de fato. Essas circunstâncias fazem com que a questão da China Comunista seja para o Japão de solução extremamente delicada e difícil.

A oposição no Japão vem, nos últimos tempos, apregoando, de modo coeso, o reconhecimento da República Popular da China. Mesmo no Partido Liberal Democrático, que é o partido da situação, vem crescendo o número daqueles que defendem o reconhecimento do governo da China Continental como o único legítimo, e advogam o mais rápido restabelecimento das relações diplomáticas com a mesma.

Assim, a questão da China Comunista se torna para o Japão cada dia mais complexa, por envolver também problemas de política interna.

Nestas circunstâncias, o recém anunciado plano do Presidente Nixon de visitar a China Comunista constitui para o Japão um dado relevante.

Na Assembléia Geral da Organização das Nações Unidas que se realiza atualmente, o Governo do Japão apoia a iniciativa norte-americana de admissão da China Comunista naquele organismo internacional, e poderá eventualmente concordar com a sua admissão no Conselho de Segurança, mas lutará até onde lhe for possível para que a Formosa não seja excluída das Nações Unidas.

A posição japonesa em relação às duas Chinas está a exigir uma grave resolução política, mas tudo dependerá ainda dos resultados da Assembléia Geral da Organização das Nações Unidas, da efetiva ida de Nixon a Pequim, e da evolução objetiva da situação internacional.

Gostaria, por último, de tecer algumas considerações sobre as relações entre o Japão e o Brasil. 
As relações diplomáticas entre o Japão e o Brasil foram oficialmente inauguradas em 1895 com a assinatura do Tratado de Amizade e de Comércio e Navegação. Em 1897 foram instaladas as respectivas embaixadas.

Por ocasião da Segunda Guerra Mundial, o Brasil se colocou ao lado da Liga das Nações e declarou guerra ao Japão, mas na realidade não trocou sequer um tiro com o Japão, e restabeleceu com o mesmo as relações diplomáticas, mediante a entrada em vigor do Tratado de Paz assinado em São Francisco, em 1951. Além do Acordo de Cooperação Judiciária que vem de antes da guerra, existem vários tratados em vigor entre o Japão e o Brasil, como por exemplo o Acôrdo sobre o Transporte Aéreo, o Acordo de Navegação e Colonização, o Acordo Cultural, o Acordo sobre o Centro de Treinamento em Fibras, o Acordo Consular, o Acordo para Evitar a Bi-tributaçã̃o, e o Acordo de Cooperação Técnica.

O fato mais notável, nas relações nipo-brasileiras é sem dúvida, a existência no Brasil de um Colônia Japonesa, formada pelas correntes imigratórias, e que já alcança a casa dos 700.000 (setecentos mil) membros.

A corrente imigratória dos japoneses para o Brasil começou com a vinda em 1908 da primeira leva constituída de 781 (setecentos e oitenta e um) imigrantes. Nos 33 (trinta e três) anos que precederam a Segunda Grande Guerra, declarada em 1941, ingressaram no Brasil 185.000 (cento e oitenta e cinco mil) imigrantes japoneses. Interrompida pela Guerra, a corrente imigratória voltou a estabelecer-se em 1952 sendo que até 1970 cerca de 50.000 (cinqüenta mil) japoneses haviam nesse período imigrado ao Brasil. O progresso econômico provocou no Japão a escassez da mão-de-obra e a elevação do nível de vida, de modo que o número de imigrantes vem diminuindo de ano a ano, e nos últimos tempos esse número tem sido de apenas 400 (quatrocentos) ou 500 (quinhentas) pessoas anuais.

A contribuição dos imigrantes japoneses à agricultura brasileira tem merecido uma alta apreciação tanto por parte do 
governo como do povo brasileiro, mas no após guerra vem sendo notada a tendência de aumento clos imigrantes de qualificação técnica. De 1953 (mil novecentos e cinqüienta e três) a 1970 (mil novecentos e setenta) vieram para o Brasil 1.591 (mil quinhentos e noventa e um) técnicos, esperando-se que tal número vá aumentando gradativamente.

No intercâmbio comercial, o Japão exportou ao Brasil, em 1966 (mil novecentos e sessenta e seis), US\$44.000.000 (quarenta e quatro milhões de dólares) e importou no mesmo ano US\$ 60000.000 (sessenta milhões de dólares), num volume total de US\$ 144.000 .000 (cento quarenta e quatro milhões de dólares) Mas em 1970 (mil novecentos e setenta), com as exportações do Japão somando US\$160.000,000 (cento sessenta e seis milhões de dólares) e as importações atintingindo US\$218.000.000 (duzentos e dezoito milhões de dólares), totalizando um volume de negócios de US\$ 384.000 .000 (trezentos e oitenta e quatro milhões de dólares), pode-se notar que o intercâmbio entre os dois países acusou um extraordinário crescimento, de cerca de 4 (quatro) vezes.

O Japão tem importaclo do Brasil minério de ferro, algodão, carne, açucar, café, milho e outros produtos primários, e o Brasil vem importando do Japão maquinários, aço, produtos químicos, e outras matérias-primas industriais, de modo que o comércio entre os dois países vem se desenvolvendo sob a forma de recíproca complementação. Espera-se que esse intercâmbio continui a se expandir.

No tocante à cooperação econômica, tem-se que até março de 1970 (mil novecentos e setenta) houve investimentos privados japoneses no Brasil da ordem de US\$184.000 000 (cento e oitenta e quatro milhões de dólares), e financiamentos de US\$176.000.000 (cento e setenta e seis milhões de dólares), num total de US\$360.000.000 (trezentos e sessenta milhões de dólares) 
Como em março de 1969 (mil novecentos e sessenta e nove) tais aplicações eram de US $\$ 213.000 .000$ (duzentos e treze milhões de dólares), verifica-se que em um ano houve um aumento de US\$147.000.000 (cento e quarenta e sete milhões de dólares)

Sobem a 95 (noventa e cinco) as empresas que representam investimentos japoneses no Brasil, das quais as maiores são as Usinas Siderúrgicas de Minas Gerais (Usiminas) e os Estaleiros Ishikawajima do Brasil, sendo que os investimentos estão diversificados nos mais diferentes setores, desde a indústria química, indústria textil, a indústria de máquinas de fiação e tecelagem, indústria de máquinas agrícolas, a indústria de fertilizantes, até a indústria de materiais elétricos.

Ainda no campo financeiro e comercial, as atividades das empresas japonesas no Brasil tem sido intensas.

Quanto à cooperação técnica, tem-se que, desde 1958 (mil novecentos e cinquenta e oito) até hoje, só em nível governamental, 248 (duzentos e quarenta e oito) técnicos brasileiros foram treinados no Japão, e 52 (cinquienta e dois) especialistas japoneses vieram ao Brasil prestar cooperação de natureza técnica. Além disso, gostaria de citar a criação no Recife do Centro de Treinamento em Fibras, a cooperação médica à Universidade de Pernambuco, o envio de grupos de pesquisa para os mais diversos setores, a doação de equipamentos, entre os fatos que representam a cooperação japonesa. Dentro de pouco tempo deverá vir ao Brasil um Grupo de Estudos Básicos a fim de colaborar no plano de desenvolvimento do $\mathrm{Va}$ le do Ribeira.

E grato assinalar que o govêrno e o povo brasileiros reconhecendo cada vêz mais profundamente o valor da contribuição dos imigrantes japoneses, e da cooperação econômica e técnica do Japão, vêm procurando fortalecer as relações de amizade e a mútua cooperação, entre os dois países. 
Mas em virtude de situar-se geograficamente em polos opostos, e de falar línguas totalmente diferentes, o conhecimento mútuo entre os dois povos não me parece suficiente, apesar da grande evolução dos meios de comunicação.

Como já disse antes, o Japão deverá buscar as matérias-primas de que necessita, cada vez mais neste país de ricos recursos naturais que é o Brasil, enquanto o Brasil procurará obter no Japão os capitais, bens de capital e a tecnologia avançada, estabelecendo um intercâmbio ideal de recíproca complementação.

Por isso mesmo, parece-me que as relações entre os países devem ser estreitadas ainda mais.

Gostaríamos, todos nós, de continuar trabalhando para esse objetivo comum.

Quero aqui finalizar esta minha palestra, salientando que as relações de amizade entre as nações se baseiam na mútua compreensão e conhecimento.

Por isso mesmo, sentir-me-ei feliz se a palestra desta noite puder servir para aumentar nos senhores a compreensão das coisas do Japão, e, deste modo, contribuir para o incremento das relaçães de amizade entre o Japão e o Brasil.

Pela gentil atenção de todos os senhores, o meu

Muito obrigado. 